\title{
Photodynamic Therapy (Part 1: Applications in Dentistry)
}

\author{
Nikhil Vishwas Khandge, Suchetan Pradhan, Yogesh Doshi, Atul Kulkarni, Ishan Dhruva
}

\section{ABSTRACT}

Aim: To overview the effectiveness of photodynamic therapy (PDT) along with different types of photosensitizers and the lasers associated with them.

Background: Administration of drugs for oral infections and pathologies are accompanied with a lot of limitations like lack of patient compliance, microbial resistance in the biofilm, systemic side effects, failure on the antibiotics to act on non-perfused areas, allergy and the limitation of spectrum of microorganisms affected. To overcome this, an effective and an alternative therapy needs to replace the conventional treatment. Indians since ancient past have been using the extracts of Psoralea corylifolia which contains furocoumarins, given orally, and followed by exposure to sunlight in order to treat vitiligo. Thus, PDT was investigated in the past as a promising alternative if not replacement for the conventional treatment.

Clinical significance: It has been seen that various combinations of photosensitizer and lasers are effective against a broad spectrum of microorganisms. Porphyrin photosensitizers and temoporfin have been used successfully in the past against premalignant and malignant intraoral lesions. They are excellent options for palliative treatment for cases refractory to conventional therapy. Phenothiazinium photosensitizers like methylene blue and toluidine blue have shown to be effective against bacterias, viruses and fungal infections. Hence, they are effective tools for the treatment of refractory periodontics and endodontic infections.

Conclusion: With the revolution of lasers in the field of dentistry and oncology, a new minimally invasive and precise approach towards the pathology is being developed. However, further research needs to be done in terms of development of newer formulations and dosimetry for more consistent results free of side effects.

Keywords: Antibiotic resistance, Porphyrin, Temoporfin, Phenothiazinium, Refractory.

How to cite this article: Khandge NV, Pradhan S, Doshi Y, Kulkarni A, Dhruva I. Photodynamic Therapy (Part 1: Applications in Dentistry). Int J Laser Dent 2013;3(1):7-13.

Source of support: Nil

Conflict of interest: None

\section{INTRODUCTION}

It has been an established concept that microorganisms are the main culprits for periodontal ${ }^{1,2}$ and endodontic diseases. ${ }^{3-5}$ In both Periodontics and Endodontics, the approach toward the pathology is mechanical debridement of the affected area along with local and systemic antimicrobials. The disadvantages of antimicrobial agents range from lack of patient compliance, microbial resistance in the biofilm, ${ }^{6,7}$ systemic side effects, failure on the antibiotics to act on non-perfused areas, allergy and limitation of spectrum of microorganisms affected. Strategies employed by microorganisms resisting antibiotics have been thickening of their outer wall, encoding of new proteins which prevent the penetration of drugs, onset of mutants deficient in those porin channels allowing the influx of externally added chemicals, etc. ${ }^{8-10}$ The solution to these problems is unknown till date. Treatment using light and light activated compounds is referred back from ancient times, and was used to treat a wide variety of disorders and malaise. ${ }^{11-13}$ But the breakthrough came when first report emerged on light-absorbing properties and fluorescence of various dyes, it became clear that dye excitation by light exerts destructive action in biologic systems. This so-called 'photodynamic action' was described as a process in which light, after being absorbed by dyes, sensitizes organisms for visible light-inducing cell damage. Photodynamic therapy (PDT) is based on the principle that a photoactivable substance that is photosensitizer binds to the target cell and can be activated by light of a suitable wavelength. Photodynamic is also known as photoactivated disinfection (PAD) or photoactivated chemotherapy (PACT).

\section{HISTORY}

The concept of treatment with light and photoactive compounds can be traced back over 6000 years to the ancient Egyptians who used light-sensitive substances (psoralens) by crushing leaves of plants related to parsley with sunlight to treat sunburns. Reference to the use of a plant extract for the restoration of skin pigmentation was made in $1400 \mathrm{BC}$ and phototoxic effects of psoralens were described in 1250 AD. ${ }^{14}$ Ancient Indians also believed that vitiligo could be treated by the combination of extracts of Psoralea corylifolia and light. But the actual breakthrough came by Finsen's pioneering research in 1901 in which he showed that skin tuberculosis could be successfully treated with natural and artificial ultraviolet light. German medical student Raab et al. in 1900 first studied photodynamic reaction using cultures of Paramecium and acridine an organic dye. The first medical use of chemically enhanced phototherapy (other than for restoration of pigmentation) was reported by Jesionek and Tappeiner in 1905 when they treated five basal cell carcinomas by injecting eosin into the tumor and exposing it to light reporting three cures. The essential involvement of light and oxygen in the process was shortly thereafter demonstrated by von Tappeiner, ${ }^{15}$ who coined 
the term 'photodynamic'. Haxthausen and Hausmann in 1908 were the first to suggest that hematoporphyrin was a photodynamic photosensitizer. In 1960, Theodore Maiman, a scientist with the Hughes Aircraft Corporation, developed the first working laser device which emitted a deep red colored beam from a ruby crystal (Coluzzi, 2004). Wilson et al. (1993) proved the effect of cyanide photosensitizer on Gram-negative and Gram-positive species. Ackrayd (1999) used aminolevulinic acid-induced PDT for treatment of adenocarcinoma. Thereafter, in the recent past many combinations of lasers and photosensitizers were tried and different parameters with varying successes.

\section{Mechanism of Action}

The three components of PDT are oxygen, photosensitizer and light (Fig. 1).

When a photosensitizer is administered to the patient and irradiated with a suitable wavelength, it goes to an excited state from its ground state. This excited state can then decay back to its ground state or form the higher energy triplet state. ${ }^{16,17}$ The interaction between biomolecules and triplet state photosensitizers can be of two types as follows:

Type I: It involves electron/hydrogen transfer directly from the photosensitizer, producing ions, or electron/ hydrogen removal from a substrate molecule to form free radicals. These radicals react rapidly with oxygen, resulting in the production of highly reactive oxygen species (superoxide, hydroxyl radicals, and hydrogen peroxide).

Type II: The reactions produce electronically excited and highly reactive state of oxygen known as singlet oxygen. In PDT, it is difficult to distinguish between the two reactions mechanisms.

A contribution from both types I and II processes indicates that the mechanism of damage is dependent on both oxygen tension and photosensitizer concentration (Figs 2 and 3).

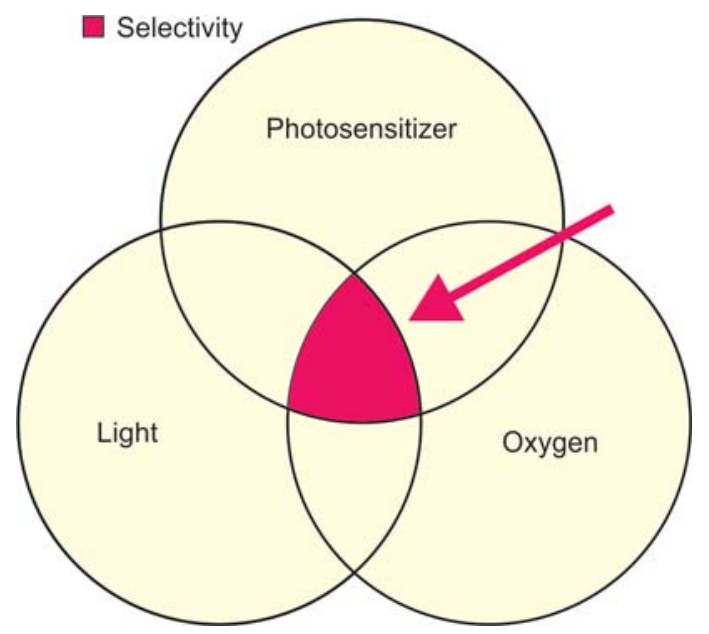

Fig. 1: Factors for successful photodynamic therapy

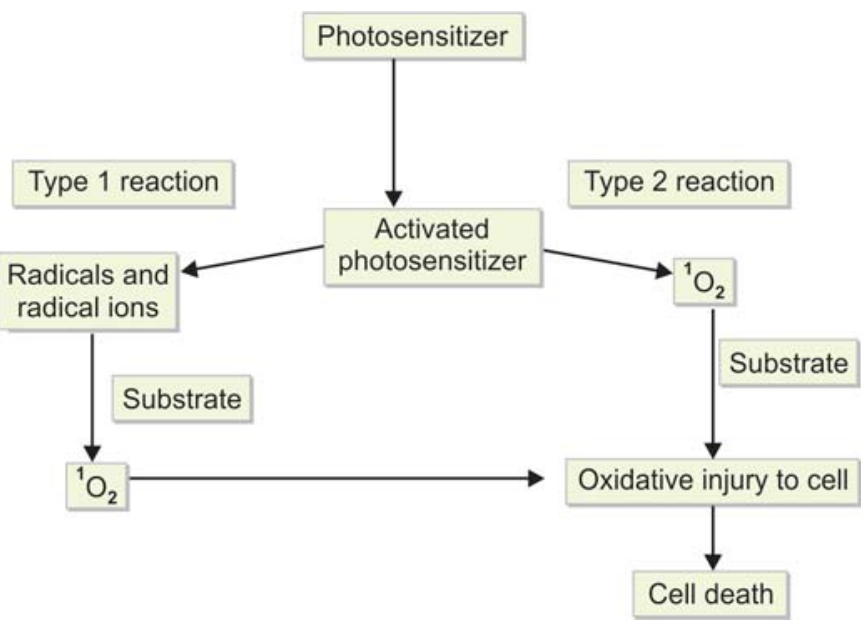

Fig. 2: Factors for successful photodynamic therapy

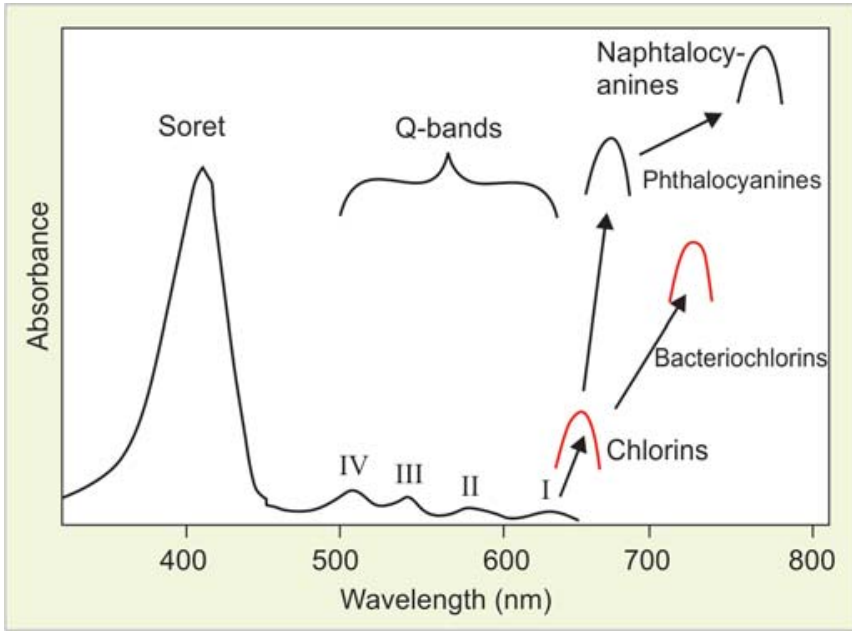

Fig. 3: Absorption of various chromophores by different wavelengths

In this process free radicals are formed which then produces an effect that is toxic to the cell. ${ }^{18,19}$ The half-life of oxygen radicals is only about a few nanoseconds hence this cytotoxic molecule can diffuse only up to $20 \mathrm{~nm}$ in cells (Moan et al., 1991). Thus, these photosensitizers localize in the mitochondria, plasma membrane, endoplasmic reticulum and Golgi complex at concentrations sufficient for mediating cytotoxicity. Due to the very short half-life of oxygen radicals, measured in nanoseconds, this cytotoxic molecule can diffuse only up to $20 \mathrm{~nm}$ in cells (Moan et al., 1991). Also the reactive end products of this pathway results in a rapid cyto- and vasculotoxicity which are the basis of PDT. ${ }^{20}$ Research in a number of laboratories has demonstrated the potential of PDT as a treatment for localized microbial infections. ${ }^{21-23}$ PDT has shown to be active against both Gram-positive and Gram-negative organisms. ${ }^{23}$

Tim Maisch et al. (2004) studied the general photobiological and photochemical aspects and stated: 
The photodynamic activity to induce cell damage or death is determined by five important photophysical/ photochemical properties including the following:

1. An overall lipophilicity and ionization of the photoreactive dyes

2. The molecular extinction coefficient

3. Quantum yield of the triplet state formation $U T$

4. Redox potentials of the excited states of the $\mathrm{P}_{\text {red }}^{\mathrm{S}}$ or $\mathrm{PS}^{\mathrm{T}}{ }_{\text {red }}$, if the reaction follows the type I mechanism or

5. The quantum yield of the singlet oxygen generation, if the reaction occurs by a type II photosensitization.

\section{Applications of Photoactivated Disinfection (Based on Wilson and Wilson)}

- Treating periodontal pockets

- Plaque-infected cervical regions of teeth and implants

- Disinfecting carious dentin prior to restoration

- Destroying cariogenic microbes for caries treatment and prevention

- Disinfecting root canals

- Disinfecting oral tissues prior to and during surgery

- Treating oral candidiasis in immunocompromised patients

- Treating denture stomatitis.

\section{Applications in Endodontics}

Modern endodontics is striving toward minimally invasive techniques to obtain a perfectly sterile canal. Many techniques like root canal medicaments, irrigants and irrigating techniques have been tried in the past with limited success. Currently, there is an emergence of bacteria with multiple resistances, and there is a need for alternative antimicrobial approaches. ${ }^{24-28}$ The combination of conventional endodontic therapy and PDT has been shown as an effective approach in reducing bacterial load in vitro and in vivo models. ${ }^{4,28-32}$

In comparison with the conventional hypochlorite irrigation it is certain that PDT has shown promising results. ${ }^{32}$ PDT has shown to be effective against Grampositive $^{33,34}$ as well as Gram-negative endodontic pathogens. ${ }^{35}$ In particular E. faecalis which has shown high resistance to the conventional debridement techniques due to limitations of mechanical debridement of instruments and lack of penetration of irrigants. Research has shown high susceptibility to phenothiazinium PDT in which up to 99.99\% reduction of CFU was seen. ${ }^{36}$ PDT cannot replace the conventional cleaning and shaping done by mechanical instruments. However, it certainly is a very useful adjuvant in obtaining consistent results. ${ }^{37}$ Methylene blue and toluidine blue seem to be the ideal photosensitizers for canal sterilizations. A $0.5 \mathrm{ml}$ toluidine blue ( $50 \mu \mathrm{g} / \mathrm{ml})$ is injected inside the canal and allowed to wait for 5 minutes followed by irradiation using a $50 \mathrm{~mW}$ diode laser (Ga-Al-As) at a wavelength of $633 \mathrm{~nm}$ with an endodontic diffuser fiber of $200 \mu \mathrm{m}$ for 1 to 2 minutes. The fiber should be $1 \mathrm{~mm}$ short of the apex and should be moved in a spiral manner from apical third to coronal third. Also methylene blue $50 \mu \mathrm{g} / \mathrm{ml}$ can be used with $670 \mathrm{~nm}$ wavelength successfully up to $99.74 \%{ }^{38}$ Since, it is used at low powered doses it is completely safe to use as there is no significant rise in temperature and also significantly less cytotoxicity than conventional treatment methods ${ }^{39,40}$ (Figs 4 to 7).

\section{Applications of PDT in the Management of Tumors}

In the past numerous modalities have been tried for successful treatment of intraoral malignancies with varied success. The conventional treatment options were crude and extremely invasive apart from being nonspecific resulting in a high morbidity rate. Besides, a chance of recurrence
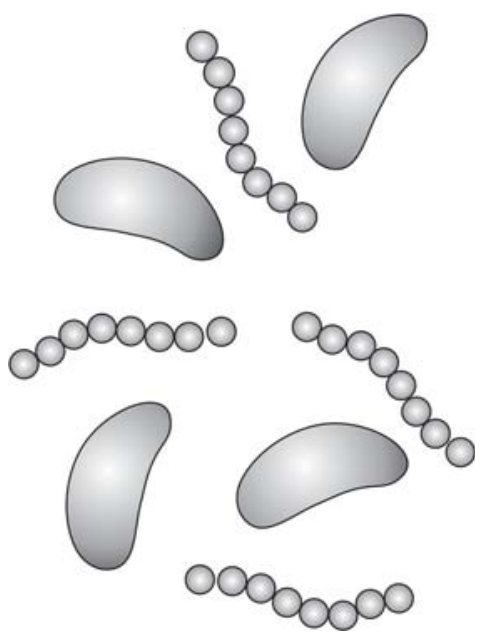

Fig. 4: Microorganisms inducing pathology

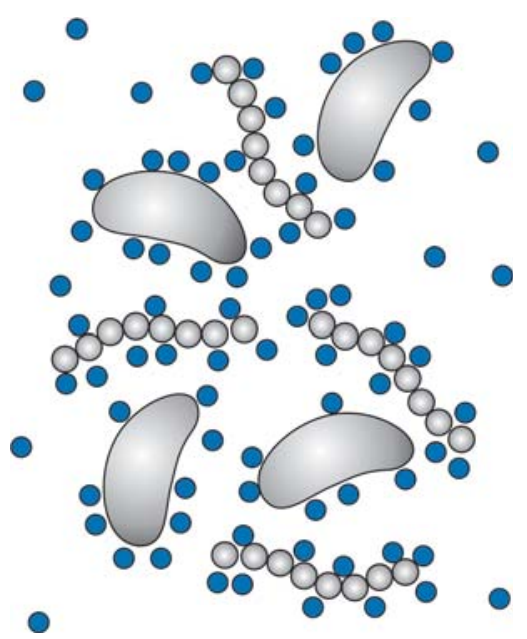

Fig. 5: After staining with suitable dye 


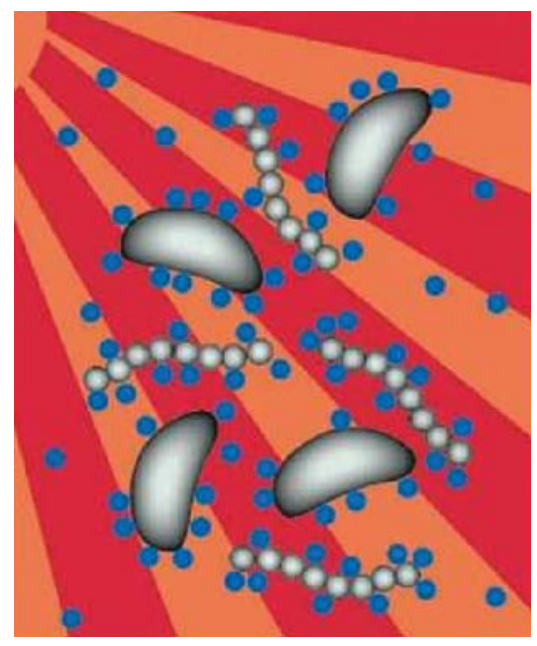

Fig. 6: Exposure to a suitable wavelength

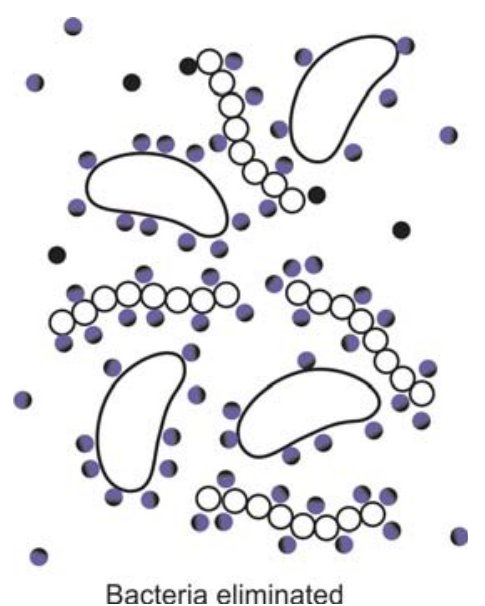

Fig. 7: Photodynamic kill

always existed. Chemotherapy had its own adverse effects on the body systemically. In such a scenario, a treatment modality which was precise, minimally invasive, high efficiency and lesser morbidity was desperately awaited. In the past 2 decades PDT has gained popularity and is being extensively used as an adjunct to eradication of superficial malignancies in the oral cavity because of its tumor selectivity. This tumor selectivity of PDT is on account of localization of the photosensitizer in the tumor and controlled activation of the photosensitizer by illumination of only the tumor region allowing precise and minimally invasive eradication of the malignancy. ${ }^{41}$ The reason for selective uptake of the photosensitizers by the tumor can be low $\mathrm{pH}$ (which facilitates cellular uptake), increased vascular permeability, increased production of collagen that binds porphyrins, tumor infiltration by macrophages that are efficient traps for hydrophobic photosensitizers, greater proliferative rates of neoplastic cells, a poor lymphatic drainage, high expression of LDL receptors on tumor cells (many photosensitizers bind to LDL), (Moan et al., 1992; 2003).The singlet oxygen is the primary cytotoxic agent responsible for photobiological activity, ${ }^{42}$ however, type I (radical) reactions could play a supporting role. The antitumor effects of PDT result from three interdependent processes: Direct tumor cell kill, damage to the vasculature, and activation of a nonspecific immune response (Golab et al., 2000; van Duijnhoven et al., 2003; Abels, 2004). Binding the photosensitizers to molecular delivery systems, such as growth factors or monoclonal antibodies that are characterized by high affinity for target tissues can also increase their tumor specificity (Konan et al., 2002). A high therapeutic ratio between tumor and skin response has been obtained by allowing at least 3 days between drug injection and exposure to the therapeutic light for 2 to $5 \mathrm{mg} / \mathrm{kg}$ doses and at least a 4-day interval for $5.0 \mathrm{mg} / \mathrm{kg}$ doses. The photosensitizing compounds should have low dark toxicity and should selectively accumulate in tumor tissue, in order to minimize skin sensitivity. ${ }^{41}$ After intensive research PDT is now being used safely in treatment of tumors but the spectrum of clinical applications is still limited, ${ }^{43,44}$ As PDT is a cold photochemical process, there is no tissue heating, and connective tissues, such as collagen and elastin are largely unaffected. As a result, many tissues heal with less scarring than that with electrocautery. Following the treatment, the premalignant/malignant tissue eventually sloughs away, and there is normal healing and reepithelization. In localized superficial lesions PDT is an excellent curative option giving PDT in advanced cases can prolong survival and improve the patient's quality of life but cannot be completely curative as far as large disseminated tumors are concerned. Deep-seated and pigmented tumors required a higher dose of drug for effective treatment than did the more superficial and nonpigmented lesions.

\section{Applications in Periodontics and Implants}

It has been proven that cells in biofilm are in physiological state that differs from their planktonic counterparts and tend to be less susceptible to antimicrobial agents. ${ }^{45}$ It also explains why systemically and locally delivered antimicrobials have always been proven unsuccessful, even when they were targeted at specific microorganisms. Successful periodontal therapy is still based on the concept of elimination of the microorganisms from the infected site ${ }^{46}$ lasers only make it easy, non-invasive and efficient. Phenothiazinium photosensitizers have shown to be safe and highly effective for periodontal infections. Scaling and root planning is to be carried out before PDT. While doing the PDT the photosensitizer is first injected in the periodontal pocket and allowed to pigment for 2 minutes. Then the fiber is inserted $1 \mathrm{~mm}$ short of the pocket and 
lased by moving in a sinusoidal manner from side to side toward the coronal third. It has been proven that PDT has found an adjunctive role in peri-implantitis ${ }^{47}$ (Figs 8 to 11).

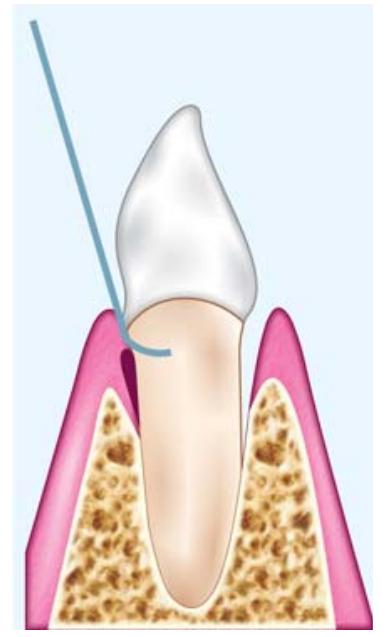

Fig. 8: Scaling

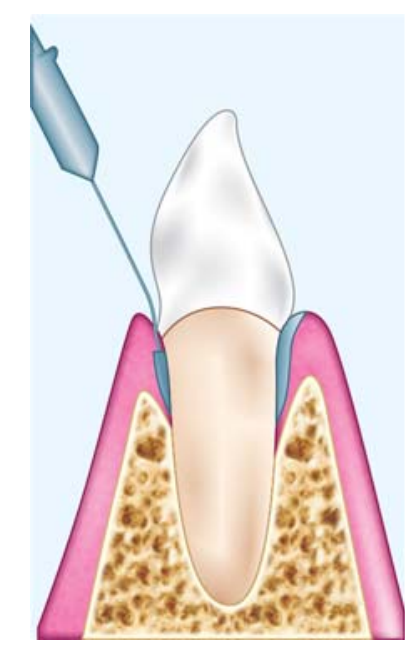

Fig. 9: Photosensitizer application

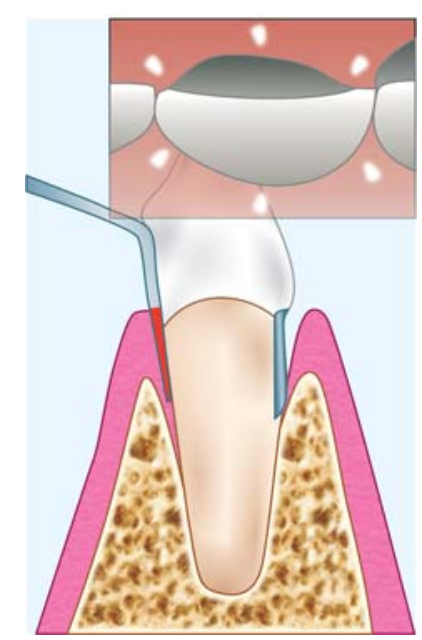

Fig. 10: Photosensitizer activation

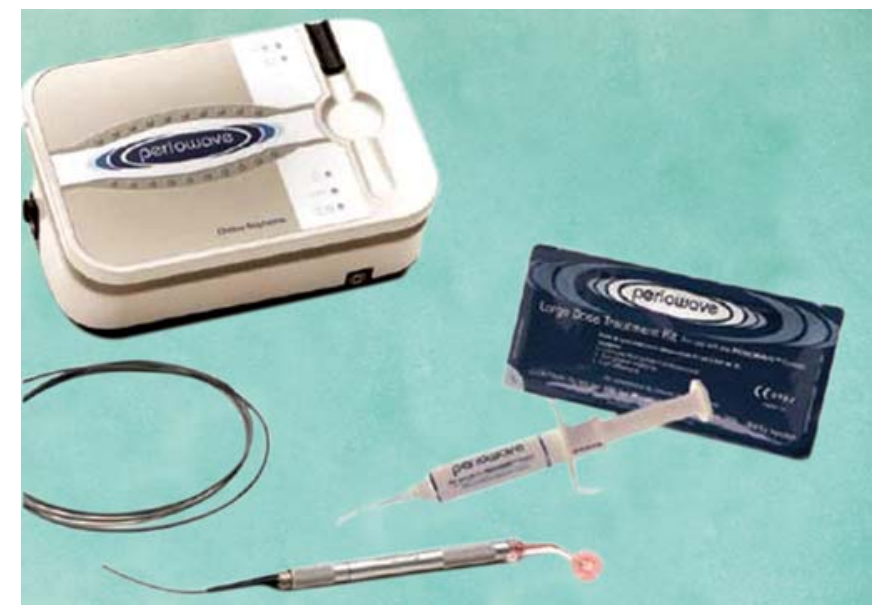

Fig. 11: PDT perio kit

\section{Advantages of PDT}

1. Minimally invasive technique with least collateral damage to normal cells enhances results and superior healing.

2. Exceedingly efficient broad spectrum of action, since one photosensitizer can act on bacteria, virus, fungi, yeasts and parasitic protozoa.

3. Efficacy independent of the antibiotic resistance pattern of the given microbial strain.

4. The therapy also causes no adverse effects such as ulcers, sloughing or charring of oral tissues.

5. Lesser chance of recurrence of malignancy.

6. Economical to use.

\section{Limitations of PDT}

Systemic administration of photosensitizer causes a period of residual skin photosensitivity due to accumulation of photosensitizers under the skin. Therefore, photosensitizers can be activated by daylight causing first or second degree burns. Hence, direct sunlight must be avoided for several hours until the drug is completely eliminated from the body.

\section{SUMMARY AND CONCLUSION}

1. Lethal photosensitization may be an effective means of eliminating periodontopathogenic bacteria from dental plaque/biofilm.

2. PDT is efficient and safe tool for treatment of chronic and aggressive periodontitis and can prove adjunctive to mechanical debridement. ${ }^{4}$

3. Development of resistance among the target organism to the PDT is unlikely. Lack of mutagenicity topical and selective action, no harm to eukaryotic/host cells are the characteristic advantages of PDT.

4. Antimicrobial PDT is an efficient method for bacterial load reduction in periodontal therapy. The treatment is 
non-invasive and can be repeated without the risk of allergies and resistance in comparison to antibiotic therapy.

5. PDT is effective even in the presence of blood (CR Rovaldi, 2000).

PDT may be an effective way to treat the bacteria linked to periodontal diseases and could provide a better option than antibiotics or other mechanical methods for treating periodontal diseases and may prove to be a promising alternative to conventional periodontal therapy in near future.

\section{REFERENCES}

1. Amano A. Disruption of epithelial barrier and impairment of cellular function by Porphyromonas gingivalis. Front Biosci 2007;12:3965-74.

2. Meyer DH, Sreenivasan PK, Fives-Taylor PM. Evidence for invasion of a human oral cell line by Actinobacillus actinomycetemcomitans. Infect Immun 1991;59:2719-26.

3. Rolph HJ, Lennon A, Riggio MP, et al. Molecular identification of microorganisms from endodontic infections. J Clin Microbiol 2001;39:3282-89.

4. Haapasalo M, Ørstavik D. In vitro infection and disinfection of dentinal tubules. J Dent Res 1987;66:1375-79.

5. Foschi F, Cavrini F, Montebugnoli L, et al. Detection of bacteria in endodontic samples by polymerase chain reaction assays and association with defined clinical signs in Italian patients. Oral Microbiol Immunol 2005;20:289-95.

6. Walker CB. The acquisition of antibiotic resistance in the periodontal microflora. Periodontol 2000 1996;10:79-88.

7. Tunger O, Dinc G, Ozbakkaloglu B, Atman C, Algun U. Evaluation of rational antibiotic use. Int J Antimicrob Agents 2000;15:131-35.

8. Boyle-Vavra S, Labischinski H, Ebert CC, Ehlert K, Daum RS. A spectrum of changes occurs in peptidoglycan composition of glycopeptide-intermediate clinical Staphylococcus aureus isolates. Antimicrob Agents Chemother 2001;45:280-87.

9. Roland KL, Esther CR, Spitznagel JK. Isolation and characterization of a gene, pmrD, from Salmonella typhimurium that confers resistance to polymixin when expressed in multiple copies. J Bacteriol 1994;176:3589-97.

10. Harder KJ, Nikaido H, Matsuhashi M. Mutants of Escherichia coli that are resistant to certain beta-lactam compounds lack the ompF porin. Antimicrob Agents Chemother 1981;20:549-52.

11. Allison RR, Mang TS, Wilson BD. Photodynamic therapy for the treatment of nonmelanomatous cutaneous malignancies. Semin Cutan Med Surg 1998;17(2):153-63.

12. Bonnett R, Berenbaum M. Porphyrins as photosensitizers. Ciba Found Symp 1989;146:40-53.

13. Dougherty TJ, Henderson BW, Schwartz S, et al. Historical perspective. In: Henderson BW, Dougherty TJ (Eds). Photodynamic therapy. New York: Marcel Dekker 1992;1-15.

14. Llano J, Raber J, Eriksson LA. Theoretical study of phototoxic reactions of psoralens. J Photochem Photobio A: Chem 2003;154:235-43.

15. von Tappeiner H. Zur kenntis der lichtwirkenden (fluoreszierenden) stoffe. Dtsch Med Wochen 1904;1:579-80.

16. Takasaki AA, Aoki A, Mizutani K, Schwarz F, Sculean A, Wang $\mathrm{C}$, et al. Application of antimicrobial photodynamic therapy in periodontal and peri-implant diseases. Periodontology 2000 2009;51:1-32.
17. Konopka K, Goslinski T. Photodynamic therapy in dentistry. J Dent Res 2007;86:694.

18. Hassan T, Parrish JA. Photodynamic therapy of cancer. In: Holland JF, Frei EI, Bast RJC, Kufe DW, Morton DL, Weisehselbaum RR (Eds). Cancer medicine (4th ed). Baltimore, MD: The William \& Wilkins Co 1996; 739-51.

19. Pfitzner A. Bacterial killing by photodynamic therapy. J Periodontol 2006;75:1343-49.

20. Allison RR, Downie GH, Cuenca R, Hu X-H, Childs CJH, Sibata $\mathrm{CH}$. Photosensitizers in clinical PDT. Photodiag Photodyn Ther 2004;1:27-42.

21. Wainwright M. Photodynamic antimicrobial chemotherapy (PACT). J Antimicrob Chemother 1998;42:13-28.

22. Wilson M. Photolysis of oral bacteria and its potential use in the treatment of caries and periodontal disease. J Appl Bacteriol 1993;75:299-306.

23. Malik Z, Hanania J, Nitzan Y. Bactericidal effects of photoactivated porphyrins - an alternative approach to antimicrobial drugs. J Photochem Photobiol B 1990;5:281-93.

24. Yoshikawa TT. Antimicrobial resistance and aging: Beginning of the end of the antibiotic era? J Am Geriatr Soc 2002;50: s226-29.

25. Hancock RE, Bell A. Antibiotic uptake into Gram-negative bacteria. Eur J Clin Microbiol Infect Dis 1988;7:713-20.

26. Livermore DM. Antibiotic resistance in staphylococci. Int J Antimicrob Agents 2001;16:3-10.

27. Agarwal R, Athar M, Urban SA, Bickers DR, Mukhtar H. Involvement of singlet oxygen in chloroaluminum phthalocyanine tetrasulfonate-mediated photoenhancement of lipid peroxidation in rat epidermal microsomes. Cancer Lett 1991;56:125-29.

28. Phoenix DA, Sayed Z, Hussain S, Harris F, Wainwright M. The phototoxicity of phenothiazinium derivates against Escherichia coli and Staphylococcus aureus. FEMS Immun Med Microbiol 2003;39:17-22.

29. Garcez AS, Nunez SC, Hamblin MR, Ribeiro MS. Antimicrobial effects of photodynamic therapy on patients with necrotic pulps and periapical lesion. J Endod 2008;34:138-42.

30. George S, Kishen A. Influence of photosensitizer solvent on the mechanisms of photoactivated killing of Enterococcus faecalis. Photochem Photobiol 2008;84:734-40.

31. Bergmans L, Moisiadis P, Huybrechts B, Van Meerbeek B, Quirynen M, Lambrechts P. Effect of photo-activated disinfection on endodontic pathogens ex vivo. Int Endod J 2008;41:227-39.

32. Bonsor SJ, Nichol R, Reid TM, Pearson GJ. An alternative regimen for root canal disinfection. Br Dent J 2006;201:101-05.

33. Tegos GP, Anbe M, Yang C, et al. Protease-stable polycationic photosensitizer conjugates between polyethyleneimine and chlorin(e6) for broad-spectrum antimicrobial photoinactivation. Antimicrob Agents Chemother 2006;50:1402-10.

34. Fimple JL, Fontana CR, Foschi F, et al. Photodynamic treatment of endodontic polymicrobial infection in vitro. J Endod 2008;34:728-34.

35. Demidova TN, Hamblin MR. Effect of cell-photosensitizer binding and cell density on microbial photoinactivation. Antimicrob Agents Chemother 2005;49:2329-35.

36. Fonseca MB, Junior PO, Pallota RC, Filho HF, Denardin OV, Rapoport A, et al. Photodynamic therapy for root canals infected with Enterococcus faecalis. Photomed Laser Surg 2008 Jun;26(3):209-13. 
37. Lambrechts P, Huybrechts B, Moisiadis P, Bergmans L, Mattar D, Teughels W, et al. Photoactivated disinfection: Paintball endodontics. Roots 2007;2:28-43.

38. Fonseca MB, Júnior PO, Pallota RC, Filho HF, Denardin OV, Rapoport A, et al. Photodynamic therapy for root canals infected with Enterococcus faecalis. Photomed Laser Surg 2008 Jun;26(3):209-13.

39. George S, Kishen A. Advanced noninvasive light-activated disinfection: Assessment of cytotoxicity on fibroblast versus antimicrobial activity against Enterococcus faecalis. J Endod 2007;33:599-602.

40. Xu Y, Young MJ, Battaglino RA, et al. Endodontic antimicrobial photodynamic therapy: Safety assessment in mammalian cell cultures. J Endod 2009;35:1567-72.

41. DeRosa MC, Crutchley RJ. Photosensitized singlet oxygen and its applications. Coordination Chemistry Reviews 2002;233234:351-71.

42. Garcez AS, Nuñez SC, Hamblim MR, Suzuki H and Ribeiro MS. Photodynamic therapy associated with conventional endodontic treatment in patients with antibiotic-resistant microflora: A preliminary report. J Endod 2010 Sep;36(9): 1463-69.

43. Brown SB, Brown EA, Walker I. The present and future role of photodynamic therapy in cancer treatment. Lancet Oncol 2004;5:497-508.

44. Huang Z. A review of the progress in clinical photodynamic therapy. Technol Cancer Res Treatment 2005;4:283-93.

45. Zanin ICJ, Maristela ML, Rodrigues LKA, Pimenta LAF, Hofling JF, Goncalves RB. Photosensitization of in vitro Biofilms by toluidine blue $\mathrm{O}$ combined with a light emitting diode. Eur J Oral Sci 2006;114; 64-69.
46. Overman PR. Biofilm: A new view of plaque. J Contemp Dent Pract 2000;1(3):18-29.

47. Shibli JA, Martins MC, Nociti FH Jr, Garcia VG, Marcantonio E Jr. Treatment of ligature-induced peri-implantitis by lethal photosensitization and guided bone regeneration: A preliminary histologic study in dogs. J Periodontol 2003 Mar;74(3):338-45.

\section{ABOUT THE AUTHORS}

\section{Nikhil Vishwas Khandge (Corresponding Author)}

Diploma in Laser Dentistry, IALD, AALZ (SOLA), Private Practice Mumbai, Maharashtra, India, e-mail: nikhilkhandge@gmail.com

\section{Suchetan Pradhan}

MDS (Prosthodontics), M.Sc. Laser Dentistry, Germany, Emdola European Union

\section{Yogesh Doshi}

Senior Lecturer, Department of Periodontics, PDU Dental College Solapur, Maharashtra, India

\section{Atul Kulkarni}

Professor and Head, Department of Oral and Maxillofacial Surgery PDU Dental College, Solapur, Maharashtra, India

\section{Ishan Dhruva}

Postgraduate Student, Department of Periodontics, Bharati Vidyapeeth Dental College, Pune, Maharashtra, India 